\title{
Developing and testing an online breastfeeding training among undergraduate nursing students
}

\author{
Rosina Cianelli ${ }^{* 1}$, Natalia Villegas ${ }^{1}$, Khitam Azaiza ${ }^{1}$, Shakira Henderson ${ }^{1,2}$, Mary Hooshmand ${ }^{1}$, Nilda Peragallo \\ ${ }^{1}$ School of Nursing and Health Studies, University of Miami, Coral Gables, USA \\ ${ }^{2}$ South Miami Hospital, Miami, Florida, USA
}

Received: September 23, 2014

DOI: $10.5430 /$ cns.v3n1p82
Accepted: November 18, 2014 Online Published: December 1, 2014

URL: http://dx.doi.org/10.5430/cns.v3n1p82

\begin{abstract}
The benefits of breastfeeding for mothers and babies have been well documented in the scientific literature, with new evidence about the benefits continuing to emerge. The Surgeon General's call to action to support breastfeeding recommends mandatory breastfeeding education and training for all healthcare providers that deliver care to mothers and babies. The purpose of this study is to analyze the development of an online computer based breastfeeding training (BT) and the preliminary outcomes of this training. The development of this training included consultation with content and technology experts. The collection of preliminary outcomes related to breastfeeding knowledge data and evaluation of the online BT was pre and posttest study. Eighty six undergraduate nursing students completed the online BT using Blackboard Learn. The online component of the BT consisted of five modules with a combined length of approximately 16 hours. After the completion of the modules, the students increased their levels of knowledge related to breastfeeding and the majority believed that they were fully able to perform skills to support breastfeeding. The results of this study indicate that a successful BT for nursing students can be effectively designed, which can in the future be disseminated to other healthcare providers and students. In addition, this online BT was cost-efficient and effective in improving students' knowledge and skills to support breastfeeding.
\end{abstract}

Key Words: Breastfeeding, Education, Nurses, Nursing students, Healthcare providers, Online

\section{Introduction}

Global and national initiatives have been implemented to increase the proportion of mothers who breastfeed. The World Health Organization (WHO)/United Nations Children's Fund (UNICEF) ${ }^{[1]}$ considers breastfeeding as the best practice and has deemed it the best standard of nutrition for children. The benefits of breastfeeding for mothers and babies have been well documented in scientific literature, and new evidence about breastfeeding benefits continue to emerge from the scientific community. ${ }^{[2,3]}$

Action items 9 and 10 of the U.S. Surgeon General's call to action to support breastfeeding specifically recommend mandatory breastfeeding education and training for all healthcare providers that deliver care for mothers and babies. ${ }^{[4]}$ Effective training of healthcare providers in breastfeeding education has been a research interest for several years and remains until today. ${ }^{[5-7]}$ Healthcare providers who are educated and trained to promote, support, and protect breastfeeding in the hospital can directly improve (1) breastfeeding initiation rates during the hospital stay, (2) breast milk feedings in critically ill infants, and (3) breastfeeding duration rates post discharge. ${ }^{[8,9]}$

Nurses are among the most influential healthcare providers

\footnotetext{
${ }^{*}$ Correspondence: Rosina Cianelli; Email: rcianelli@miami.edu; Address: School of Nursing and Health Studies, University of Miami, 5030 Brunson Ave. Miami, FL 33146 U.S.
} 
and are the largest group providing care to mothers and infants. However, in the U.S., nurses do not receive sufficient education and/or training in nursing school or in the workplace to assist mothers who want to breastfeed. ${ }^{[10]} \mathrm{Be}-$ cause of insufficient nurse training in breastfeeding, premature formula supplementation, and cessation of breastfeeding in the hospital and post discharge, mothers lack knowledge about the importance of breastfeeding. ${ }^{[1]}$ Therefore, it is not surprising that the U.S. ranks 37 on a worldwide breastfeeding policy. ${ }^{[12]}$

To address the need for breastfeeding education and training for healthcare professionals and nurses in particular, BabyFriendly USA, a national accreditation body for evidencedbased lactation support practices within the hospital setting, mandates that healthcare providers caring for lactating women have at least 20 hours of breastfeeding didactic education. ${ }^{[13]}$ It is important to mention that exclusive breastfeeding rates are heavily influenced by hospital policies as well as nursing and medical practices. ${ }^{[9,14,15]}$ The recommended curriculum is the UNICEF/WHO ${ }^{[16]} 20$-hour Breastfeeding Training (BT) for healthcare providers. Currently, this 20-hour training is commercially available from several accredited breastfeeding and lactation education providers using instructor-led classroom learning methodology.

Over 21,000 healthcare facilities in 152 countries have achieved Baby Friendly accreditation. As a result of this international success, an effort to create positive environments that support the breastfeeding mother and enhance the benefits of breastfeeding has led to the emergence of 182 Baby Friendly accredited healthcare facilities within the United States. The Baby Friendly Hospital Initiative (BFI) focuses on intensive BT for frontline maternal-child healthcare providers. Nurses make up the majority of this group. ${ }^{[17]}$

In order to overcome the existing barriers to effective breastfeeding, the U.S. Department of Health \& Human Services, Office of the Surgeon General ${ }^{[4]}$ identified the following effective strategies: (1) education for all healthcare professionals, (2) patient access to culturally sensitive and current evidence-based information, (3) compliance with the "Baby-Friendly" 10 steps, and (4) distribution of quality patient education materials to new mothers and their significant others. ${ }^{[18]}$

During the past decade, development of education programs delivered via computer/Internet has increased; however, this has not been the case for breastfeeding education. The purpose of this study is to analyze the development of an online computer based BT and the preliminary outcomes of this training. This training is part of a hybrid/blended breastfeeding training for nursing students that included an online component and an objective structured clinical examination. Only the online component and the preliminary outcomes of this training will be presented in this study.

\section{Method}

The data reported in this article was derived from work completed in two stages. The first stage described the development of the online component of the BT with a technologybased instruction using Blackboard Learn, an online learning management system (LMS), by expert panels using the UNICEF/WHO/BFI 20-hours breastfeeding curriculum. The second stage of work was the collection of preliminary outcomes related to breastfeeding knowledge as well as the evaluation of the BT from 86 undergraduate nursing students who completed the newly online BT.

\subsection{First stage: Planning and development of the breastfeeding training}

The development of the BT consisted of putting together a panel of content experts and an expert in technology who guided the work along two important areas: (1) revision of the WHO/UNICEF /BFI 20-hours breastfeeding curriculum and its adaptation for the online BT, (2) development of the online BT component using Blackboard, and (3) development of the objective structured clinical examination (OSCE) to develop breastfeeding skills that consisted of 10 stations where the students needed to perform different activities related to breastfeeding. An examiner was present at each station to assess each student as they demonstrated specific sets of skills and behaviors in a simulated environment. Only the development of the online component and the preliminary outcomes of this training will be presented here.

The content experts' panel had three experienced professionals in maternal health and breastfeeding. They worked on the revision of the WHO/UNICEF breastfeeding curriculum to adapt its content and activities to the new online BT and in the design of activities to increase student's breastfeeding knowledge and skills. The content experts utilized the ADDIE model (analysis, design, development, implementation, and evaluation), a systematic approach, ${ }^{[19]}$ as a guide to develop the online content for the BT. In accordance with the ADDIE model, the experts assessed the students' characteristics and identified the learning objectives for the course, This stage was important because students' characteristics could impact the identification and development of appropriate activities for online settings. ${ }^{[20]}$ In the design stage, the components of the BT, including the design for the online measures, were discussed, and a draft of the BT online components was prepared for the instructional design expert.

The instructional design expert developed the technical features and the technology-based instruction of the training. The work focused on developing the content of the BT using innovative online modules in a user friendly platform. In 
addition, the expert provided technical training and support on the online course area.

The online BT has five modules, each of which includes three different sessions. The total time required to complete the five modules is 16 hours (see Table 1). Finally, the implementation and evaluation stages provided feedback to the required nursing students who participated in the online BT.

Table 1: Online breastfeeding modules

\begin{tabular}{|c|c|c|c|c|c|}
\hline Modules & Module I & Module II & Module III & Module IV & Module V \\
\hline Session 1 & $\begin{array}{l}\text { The Baby Friendly } \\
\text { Hospital Initiative }\end{array}$ & Protecting breastfeeding & $\begin{array}{l}\text { Helping with } \\
\text { breastfeeding }\end{array}$ & $\begin{array}{l}\text { Infants with } \\
\text { special needs }\end{array}$ & $\begin{array}{l}\text { Contraindications to } \\
\text { breastfeeding }\end{array}$ \\
\hline Session 3 & $\begin{array}{l}\text { Promoting breastfeeding } \\
\text { during pregnancy }\end{array}$ & $\begin{array}{l}\text { Birth practices and steps } \\
\text { for breastfeeding }\end{array}$ & Milk supply & $\begin{array}{l}\text { Breast and nipple } \\
\text { conditions }\end{array}$ & $\begin{array}{l}\text { Making your hospital or birth } \\
\text { center Baby Friendly }\end{array}$ \\
\hline
\end{tabular}

\subsection{Second stage: Breastfeeding knowledge assess- ment, evaluation and recommendations for im- provement}

The second stage of work focused on the collection of preliminary outcomes related to breastfeeding knowledge data as well as an evaluation after the students took the online BT. The design of this second stage is a pre and posttest study design. Eighty six (86) undergraduate nursing students completed the newly created online BT using the LMS on Blackboard Learn between July and November, 2013. Participants were: (1) undergraduate nursing students from the University of Miami, School of Nursing and Health Studies, (2) enrolled in a maternal health nursing course, (3) selfidentified as Internet and Blackboard users.

After participants were enrolled in the maternal health nursing course, they began the online BT course that consisted of five modules with a length of approximately 16 hours in total. Students completed a breastfeeding knowledge assessment before and after each module. In addition, at the end of the BT, the students completed an evaluation of the training. The students had the opportunity to apply their breastfeeding knowledge and skills in the clinical component of the maternal health nursing course and during the OSCE. The University of Miami Institutional Review Board approved the study.

\subsection{Measures}

Breastfeeding knowledge assessment: Breastfeeding knowledge was measured by using 74 multiple choice questions pertaining to the WHO/UNICEF/BFI 20-hour curriculum that were distributed among the five modules, each which included three sessions. Students answered between 13 and 15 multiple choice questions in each module using Blackboard. All of the questions had four possible answer options. In this study, a score was created based on the module questions (1 point was assigned for each correct answer). A higher score represented higher levels of breastfeeding knowledge. Students completed this assessment before and after each online module.
Evaluation of the online BT modules: The evaluation of the training was completed in Blackboard immediately after the students completed the BT (approximately one month after they began the online modules) using an online structured measure with an estimated length of 20 minutes. Students answered nine items reporting how confident they felt after the training to perform breastfeeding skills. Examples of these items include the following: to discuss with a pregnant woman the importance of breastfeeding; assist a mother with positioning, attaching, and feeding her baby; help mothers to have skin to skin contact immediately after birth. These items had 3 possible answers with a score from 1 to 3 points ( $1=$ "I am not able to", 2 = "I am partially able to", $3=$ "I am totally able to", total score $=9-27$ points). A higher score represented a higher confidence in breastfeeding skills after they received the online BT.

In addition, students answered 4 items reporting the (1) overall rate of the BT (possible answers excellent/good/poor), (2) quality of the BT materials (possible answers too simple/suitable/too difficult), (3) amount of work required to complete the BT (possible answers too much/suitable/very little), and (4) how much they learned from this course (possible answers very much/moderate/very little).

\subsection{Statistical analysis}

The Predictive Analytics Software (SPSS), version 18.0, was used for data analysis. Descriptive statistics were used to analyze socio demographic information and the questions regarding breastfeeding knowledge and the evaluation of the BT. To evaluate whether students' breastfeeding knowledge scores improved significantly from baseline (pretest) to their post intervention, paired $t$ test analysis was conducted. The type error rate selected for calculating the $t$ critical value was set at $\alpha=.05$.

\section{Results}

At the beginning, the online training had a section that served as a guide to the students prior to the course. The 
page included several easily navigable tabs designed to clearly address the following: (1) an overview of the training, (2) objectives of the training, (3) and instructions to complete the training.

Students were able to access one module at a time. Each online module had the following activities: (1) pre-test knowledge assessment (10-15 minutes), (2) animated PowerPoint presentations ( 2 hours), (3) video clips that showed a situation related with the contents of each module (30 minutes), (4) and finally, a post test knowledge assessment (1015 minutes).

An $80 \%$ score on each quiz was required to pass the module and to access the next module. Students were able to take the knowledge assessment several times until a score of at least $80 \%$ was attained. In this publication, the breastfeeding knowledge assessment included only the score of the first attempt after students completed the module. Once the students completed the five modules, an evaluation survey was accessible to measure their learning outcomes achievement and satisfaction with the training course.
In the online BT, all of the activities were reviewed individually. The researchers monitored the online module activities via Blackboard, ensuring that students participated regularly. Students received extra credit for their participation.

\subsection{Breastfeeding knowledge assessment}

There was a statistically significant difference between the mean scores of the pre-test and the post-test knowledge assessments in all of the five modules of the training. Mean scores in the post-test assessments were higher than the mean scores of the pre-test assessments, indicating that the students increased their levels of knowledge related to breastfeeding education. The module with the highest increase from pre-test $(\mathrm{M}=8.03, \mathrm{SD}=2.83)$ to post-test $(\mathrm{M}$ $=12.81, \mathrm{SD}=1.5)$ mean scores was Module $5, \mathrm{t}(85)=$ $15.479, p<.001$. The module with the lowest increase from pre-test $(\mathrm{M}=10.73, \mathrm{SD}=3)$ to post- test $(\mathrm{M}=12.90, \mathrm{SD}=$ 1.49) mean scores was Module $4, \mathrm{t}(85)=-6.691, p<.001$ (see Table 2).

Table 2: Breastfeeding knowledge change from pre- to post- test

\begin{tabular}{|c|c|c|c|c|c|c|c|c|}
\hline \multirow{3}{*}{ Constructs } & \multicolumn{8}{|c|}{ Paired $t$ test analysis } \\
\hline & \multirow{2}{*}{ Pre-test mean score } & \multirow{2}{*}{ Post-test mean score } & \multicolumn{2}{|c|}{$95 \% \mathrm{CI}$} & \multirow{2}{*}{ Range } & \multirow{2}{*}{$\mathbf{t}$} & \multirow{2}{*}{ df } & \multirow{2}{*}{$p$} \\
\hline & & & Lower & Upper & & & & \\
\hline Module 1 & 9.50 & 12.02 & -3.01 & -1.95 & $5-13$ & -8.682 & 85 & $<.001^{*}$ \\
\hline Module 2 & 10.40 & 12.65 & -2.79 & -1.72 & $0-14$ & -8.423 & 85 & $<.001^{*}$ \\
\hline Module 3 & 9.57 & 12.67 & -3.77 & -2.44 & $0-15$ & -9.303 & 85 & $<.001^{*}$ \\
\hline Module 4 & 10.73 & 12.90 & -2.81 & -1.52 & $1-15$ & -6.691 & 85 & $<.001^{*}$ \\
\hline Module 5 & 8.03 & 12.81 & -5.4 & -4.17 & $2-15$ & -15.479 & 85 & $<.001^{*}$ \\
\hline
\end{tabular}

\subsection{Evaluation of the BT modules}

Eighty two students completed an evaluation of the online BT. The majority of the students felt that they were fully able to perform the nine skills related to the support of breastfeeding. The students reported high levels of confidence in: "To explain the mother the importance of skin to skin contact" (84.1\%); and "To explain to the mother the importance of breastfeeding" $(82.9 \%)$. The students felt least confident in: "To position the baby to the mother breast" (45.1\%), as well as "To provide breastfeeding support for non- breastfeeding mother" $(41.4 \%)$. Table 3 contains detailed information about the nine skills to support breastfeeding.

In terms of the BT evaluation, more than a half of the nursing students $(n=54,65.9 \%)$ rated the course as "excellent", while the rest $(n=28,34.1 \%)$ rated it as "good" and none rated the course as "poor". Most of the nursing students mentioned that the quality of the training materials was suitable $(n=81,98.8 \%)$. None of the students found the edu- cational level of the material too simple or too difficult, and $1(1.2 \%)$ student did not answer the question. In relation to the amount of work during the training, $79(96.3 \%)$ of the students mentioned that it was suitable. Only two $(2.4 \%)$ of the students felt that the workload was too much and one $(1.2 \%)$ did not answer the question. In addition, the majority $(n=67,81.7 \%)$ reported that they learned "very much" from the training and the rest of the students reported their learning as moderate $(n=15,18.3 \%)$. None of the students stated that they learned very little from the course.

\section{Discussion}

Maternal-child hospitals are challenged with the required implementation of the 20-hour BT for their healthcare providers. Today's hospitals face the burdens of shrinking budgets and the potential for further loss of funds; implementing a 20-hour BT using instructor-led classroom learning has significant associated costs. Cost has been identified as one of the most significant barriers to proper education 
and training. ${ }^{[21]}$ Typically, instructor-led classrooms require the presence of an instructor and participants at the same time, and include associated costs such as refreshments, transportation, meeting places, and supplies. An alternative to the instructor-led classroom is computer-based learn- ing. This modality contains several features described in the literature as major advantages, including standardization of content, the opportunity to access the intervention from any place at any time, and cost-effectiveness, as compared with instructor-led instruction. ${ }^{[22-25]}$

Table 3: Breastfeeding skills

\begin{tabular}{|c|c|c|c|}
\hline Skills $^{*}$ & I am not able (\%) & I am partly able (\%) & I am fully able (\%) \\
\hline To explain to the mother the importance of breastfeeding & $1.2 \%$ & $15.9 \%$ & $82.9 \%$ \\
\hline To explain to the mother the importance of skin to skin contact & $2.4 \%$ & $13.4 \%$ & $84.1 \%$ \\
\hline To position the baby to the mother breast & $1.2 \%$ & $43.9 \%$ & $45.1 \%$ \\
\hline To provide breastfeeding support for mothers and babies & $0 \%$ & $30.5 \%$ & $69.5 \%$ \\
\hline To provide breastfeeding support for non-breastfeeding mother & $2.4 \%$ & $39.0 \%$ & $41.4 \%$ \\
\hline To identify supportive and non-supportive facility practices & $2.4 \%$ & $25.6 \%$ & $72.0 \%$ \\
\hline To work with co-workers to overcome breastfeeding barriers & $1.2 \%$ & $23.2 \%$ & $75.6 \%$ \\
\hline To follow the ten steps to successful breastfeeding & $0 \%$ & $32.9 \%$ & $67.1 \%$ \\
\hline To abide by the International Code of Marketing of Breast milk Substitutes & $3.7 \%$ & $23.2 \%$ & $70.7 \%$ \\
\hline
\end{tabular}

* This is a summary of the breastfeeding skills associated with the WHO questions used in breastfeeding evaluation.

The increase in breastfeeding knowledge from pre-test to post-test assessment is relevant considering that, according to the literature, nurses lack appropriate breastfeeding knowledge to support mothers who want to breastfeed. ${ }^{[10]}$ Breastfeeding knowledge and skills are essential in promoting and supporting breastfeeding. However, evidence of inadequate preparation regarding breastfeeding among healthcare providers, particularly nurses in clinical practices, continues to be a concern. ${ }^{[5,7,26,27]}$

To overcome the existing barriers to effective breastfeeding, this online BT includes the elements recommended by the U.S. Department of Health \& Human Services, Office of the Surgeon General: ${ }^{[4]}$ (1) to provide breastfeeding education; (2) to provide a culturally sensitive component and current evidence-based information to support breastfeeding; (3) to comply with "Baby-Friendly"; and (4) to provide quality education to mothers. ${ }^{[14,16,18,28,29]}$

Furthermore, the utilization of online instructional methodology allows to respond to different learning preferences and styles and to help to control training costs. ${ }^{[30]}$ This online BT has promise as an effective strategy to incorporate breastfeeding content into nursing undergraduate and graduate curricula in specific nursing courses such as maternal and pediatric nursing. The CDC also stressed that breastfeeding education needs to be built into the curricula of medical and nursing schools and educational programs for other health professionals. ${ }^{[31]}$ Improving breastfeeding education in nursing curricula could be a strong first step in preparing future nurses with the essential breastfeeding knowledge and skills needed to support breastfeeding mothers. ${ }^{[26]}$

This online instructional technology provided a standardized, cost effective, and accessible intervention, which helps to overcome cost barriers that hospital administrators confront when using instructor-led classrooms to train nurses. In the future, there is a potential to incorporate telehealth technology, further replacing the face-to-face didactic BT sessions with live telehealth educational sessions that extend beyond one classroom to multiple sites and reach additional providers across campuses and health systems. This allows for engagement with the instructor yet expands the availability of this greatly needed BT program beyond the border of the classroom. In addition, telehealth and mobile technologies can now link providers directly with families in their homes.

These modalities offer the potential to increase the breastfeeding rate by bringing a program that provides support and counseling directly to families and recipients of care to their homes and promoting family-centered care. Research has demonstrated that telehealth can reduce family cost burdens, maintain caring behaviors on the part of health care professionals, and promote caring, family-centered systems of care in local communities. ${ }^{[32]}$

The Patient Protection and Affordable Care Act ${ }^{[33]}$ mandates insurance coverage for comprehensive breastfeeding support and counseling as well as funding of supplies effective August 2012. This provides a unique opportunity for health care providers and organizations as we strive to meet the goals of Healthy People 2020. To reach these goals, current and emerging technologies, such as online learning and telehealth, can offer a unique opportunity to positively impact the breastfeeding goals across our nation. Using these technologies to reach additional healthcare providers across health systems and communities has the potential to dramatically increase the number of educated providers, who can further educate and support more women to initiate and sus- 
tain breastfeeding their infants throughout the first year of life.

\section{Limitations of the study}

Limitations of this study include the limited sample size. The sample was collected from one nursing programs from one state, which limits the generalizability of the results. Future studies can include larger sample from other universities, different nursing programs, and other geographical locations. Despite these limitations, it was possible to obtain important information regarding the breastfeeding knowledge of undergraduate nursing students.

\section{Conclusions}

The results of this study demonstrated the feasibility of designing a successful online BT training for nursing students that can in the future be disseminated to other healthcare providers and students. By demonstrating the feasibility, effectiveness, and cost-efficient of the online BT, nursing schools, and hospitals may be encouraged to adopt the online BT that has the potential to dramatically increase the number of educated providers, who can further educate and support more women to initiate and sustain breastfeeding through the improvement of their knowledge and skills to support breastfeeding.

\section{Acknowledgements}

This research was supported by the School of Nursing and Health Studies at the University of Miami, Coral Gables, Florida. The content is solely the responsibility of the authors and does not necessarily represent the official views of the School of Nursing and Health Studies at the University of Miami.

\section{Conflicts of Interest Disclosure}

The authors report no financial interests or potential conflicts of interest with grantors or other entities whose products or services are related to topics covered in this manuscript that could be construed as a conflict of interest.

\section{References}

[1] World Health Organization, United Nations Children's Fund. Protecting, promoting and supporting breastfeeding: The special role of maternity services. World Health Organization; 1989. Available from: http://whqlibdoc.who.int/publications/924 $1561300 . p d f$

[2] Eidelman AI. Breastfeeding and the use of human milk: An analysis of the American academy of pediatrics 2012 breastfeeding policy statement. Breastfeed Med. 2012 Oct; 7(5): 323-4. PMid:22946888. http://dx.doi.org/10.1089/bfm.2012.0067

[3] Toma TS, Rea MF. Benefits of breastfeeding for maternal and child health: An essay on the scientific evidence. Cad Saude Publica. 2008; 24 Suppl 2: S 235-46. PMid:18670704. http://dx.doi.o $\mathrm{rg} / 10.1590 / \mathrm{S} 0102-311 \mathrm{X} 2008001400009$

[4] U.S. Department of Health \& Human Services, Office of the Surgeon General. The Surgeon General's Call to Action to Support Breastfeeding. Washington, DC: Department of Health and Human Services. Available from: http://www.surgeongeneral.gov/library/calls/bre astfeeding/calltoactiontosupportbreastfeeding.pdf

[5] Bernaix LW, Beaman ML, Schmidt CA, et al. Success of an educational intervention on maternal/newborn nurses' breastfeeding knowledge and attitudes. J Obstet Gynecol Neonatal Nurs. 2010 Nov-Dec; 39(6): 658-66. PMid:21039848. http://dx.doi.org /10.1111/j.1552-6909.2010.01184.x

[6] Spatz DL. Report of a staff program to promote and support breastfeeding in the care of vulnerable infants at a children's hospital. J Perinat Educ. 2005 Winter; 14(1): 30-8. PMid:17273419. http: //dx.doi.org/10.1624/105812405X23630

[7] Spear HJ. Nurses' attitudes, knowledge, and beliefs related to the promotion of breastfeeding among women who bear children during adolescence. J Pediatr Nurs. 2004 Jun; 19(3): 17683. PMid:15185246. http://dx.doi.org/10.1016/j.pedn. 20 04.01 .006

[8] Chung M, Raman G, Trikalinos $\mathrm{T}$, et al. Interventions in primary care to promote breastfeeding: An evidence review for the U.S. preventive services task force. Ann Intern Med. 2008 Oct 21;
149(8): 565-82. PMid:18936504. http://dx.doi.org/10.7326 /0003-4819-149-8-200810210-00009

[9] DiGirolamo AM, Grummer-Strawn LM, Fein SB. Effect of maternity-care practices on breastfeeding. Pediatrics. 2008 Oct; 122 Suppl 2: S 43-9. PMid:18829830. http://dx.doi.org/10.1542 /peds. 2008-1315e

[10] Dodgson JE, Tarrant M. Outcomes of a breastfeeding educational intervention for baccalaureate nursing students. Nurse Educ Today. 2007 Nov; 27(8): 856-67. PMid:17257711. http://dx.doi.org /10.1016/j.nedt.2006.12.001

[11] Smith J, Dunstone M, Elliott Rudder M. Health professional knowledge of breastfeeding: Are the health risks of infant formula feeding accurately conveyed by the titles and abstracts of journal articles? J Hum Lact. 2009 Aug; 25(3): 350-8. PMid:19369684. http://dx.doi.org/10.1177/0890334409331506

[12] Save the Children International. Nutrition in the First 1,000 Days: State of the World's Mothers. 2012. Available from: http: //www . savethechildren.org/atf/cf/\%7B9def 2 ebe $-10 \mathrm{ae}-432 \mathrm{c}-9 \mathrm{bd0}-\mathrm{df} 91 \mathrm{~d} 2 \mathrm{eba} 74 \mathrm{a} \%$ D/STATEOFTHEWORLDSM OTHERSREPORT2012.PDF

[13] Watkins AL, Dodgson JE. Breastfeeding educational interventions for health professionals: A synthesis of intervention studies. J Spec Pediatr Nurs. 2010 Jul; 15(3): 223-32. PMid:20618637. http: //dx.doi.org/10.1111/j.1744-6155.2010.00240.x

[14] Baby-Friendly USA. Staff training requirements. Available from: http://www.babyfriendlyusa.org/

[15] Ebersold SL, Murphy SD, Paterno MT, et al. Nurses and breastfeeding: Are you being supportive? Nurs Womens Health. 2007 Oct; 11(5): 482-7. PMid:17897428. http://dx.doi.org/10.1111/j $.1751-486 \mathrm{X} .2007 .00216 . \mathrm{x}$

[16] UNICEF/WHO. Breastfeeding promotion and support in a BabyFriendly Hospital. A 20 hour course for maternity staff. WHO; 2006. Available from: http://www.who.int/nutrition/topi cs/BFHI_Revised_Section_3.1.pdf

[17] Baby-Friendly USA. Designed facilities. Available from: http: //www.babyfriendlyusa.org/

[18] Davis SK, Stichler JF, Poeltler DM. Increasing exclusive breastfeeding rates in the well-baby population: An evidence-based 
change project. Nurs Womens Health. 2012 Dec; 16(6): 46070. PMid:23253573. http://dx.doi.org/10.1111/j.1751-4 86X.2012.01774.x

[19] Dick W, Carey L, Carey JO. The systematic design of instruction. 6th ed. Boston, MA: Allyn \& Bacon; 2005.

[20] Amaral K, Shank J, Shibley I, et al. Designing a blended course: Using ADDIE to guide instructional design. Journal of College Science Teaching. 2011; 40(6): 80-85.

[21] Semenic S, Childerhose JE, Lauziere J, et al. Barriers, facilitators, and recommendations related to implementing the baby-friendly initiative (BFI): An integrative review. J Hum Lact. 2012 Aug; 28(3): 317-34. PMid:22628290. http://dx.doi.org/10.1177/08903 34412445195

[22] Kiene SM, Barta WD. A brief individualized computer-delivered sexual risk reduction intervention increases HIV/AIDS preventive behavior. J Adolesc Health. 2006 Sep; 39(3): 404-10. PMid:16919803. http://dx.doi.org/10.1016/j.jadohealt h. 2005.12.029

[23] Pequegnat W, Rosser BR, Bowen AM, et al. Conducting internetbased HIV/STD prevention survey research: Considerations in design and evaluation. AIDS Behav. 2007 Jul; 11(4): 50521. PMid:17053853. http://dx.doi.org/10.1007/s10461-0 06-9172-9

[24] Ritterband LM, Thorndike FP, Gonder-Frederick LA, et al. Efficacy of an internet-based behavioral intervention for adults with insomnia. Arch Gen Psychiatry. 2009 Jul; 66(7): 692 8. PMid:19581560. http://dx.doi.org/10.1001/archgenps ychiatry.2009.66

[25] Roberto AJ, Zimmerman RS, Carlyle KE, et al. The effects of a computer-based pregnancy, STD, and HIV prevention intervention: A nine-school trial. Health Commun. 2007; 21(2): 115-
24. PMid:17523857. http://dx.doi.org/10.1080/104102307 01306990

[26] Ahmed A, Bantz D, Richardson C. Breastfeeding knowledge of university nursing students. MCN Am J Matern Child Nurs. 2011 NovDec; 36(6): 361-7. PMid:22019915. http://dx.doi.org/10.10 97/NMC. Ob013e31822de549

[27] Register N, Eren M, Lowdermilk D, et al. Knowledge and attitudes of pediatric office nursing staff about breastfeeding. J Hum Lact. 2000 Aug; 16(3): 210-5. PMid:11153154. http://dx.doi.org/1 $0.1177 / 089033440001600305$

[28] Cadwell K, Turner-Maffei C. The curriculum in support of the ten steps to successful breastfeeding. United States: Healthy Children Project Incorporated; 2002. PMid:11753428.

[29] Cadwell K. Reaching the goals of "healthy people 2000" regarding breastfeeding. Clin Perinatol. 1999 Jun; 26(2): 527-37. PMid:10394500.

[30] Hellings P, Howe C. Assessment of breastfeeding knowledge of nurse practitioners and nurse-midwives. J Midwifery Womens Health. 2000 May-Jun; 45(3): 264-70. http://dx.doi.org/10. 1016/S1526-9523(00) 00010-6

[31] Shealy K, Ruowei L, Benton-Davis S, et al. The CDC guide to breastfeeding interventions. Atlanta: U.S. Department of Health and Human Services, Centers for Disease Control and Prevention; 2005. Available from: http://www.cdc.gov/breastfeeding/ pdf/breastfeeding_interventions.pdf

[32] Hooshmand MA. Comparison of telemedicine to traditional faceto-face care for children with special health care needs: Analysis of cost, caring, and family- centered care, family cost survey, caring professional scale, measure of processes of care 20-item scale. [PhD]. University of Miami; 2010.

[33] United States Congress. Patient protection and affordable care act; 2010. Washington D.C.: U.S. Government Information; 2010. 